\title{
Can the International Classification of Functioning, Disability and Health (ICF) be used to understand risk factors for falls in older Australian women?*
}

\author{
Afsoon Hassani Mehraban ${ }^{1}$ Lynette Mackenzie ${ }^{2 \#}$, Julie Byles $^{3}$, Richard Gibson ${ }^{3}$, \\ Cassie Curryer ${ }^{3}$ \\ ${ }^{1}$ Occupational Therapy Department, Rehabilitation Research Center, School of Rehabilitation Sciences, Iran University of Medical \\ Sciences, Tehran, Iran \\ ${ }^{2}$ Discipline of Occupational Therapy, University of Sydney, Sydney, Australia; \\ \#Corresponding Author: Lynette.Mackenzie@sydney.edu.au \\ ${ }^{3}$ Research Centre for Gender Health and Ageing, University of Newcastle, Newcastle, Australia
}

Received 24 October 2013; revised 28 November 2013; accepted 2 December 2013

Copyright (C) 2013 Afsoon Hassani Mehraban et al. This is an open access article distributed under the Creative Commons Attribution License, which permits unrestricted use, distribution, and reproduction in any medium, provided the original work is properly cited.

\section{ABSTRACT}

Purpose: To evaluate the relevance and accuracy of determining and predicting risk factors for falls in older women using the International Classification of Functioning, Disability and Health (ICF). Methods: We tested the accuracy of the ICF against risk of falls amongst 568 community dwelling participants of the Australian Longitudinal Survey on Women's Health (ALSWH). We linked health-related variables to the ICF using ten linking rules. The logistic regression analysis evaluated the relationship between the variables and the outcome of falls. Self-report surveys measured daily functioning, health service use, medications, housing and social support. Results: Variables aligned with the ICF components of body function, health conditions, environment, activity and participation (ADL/IADL), and general health were significantly associated with falls. Discussion and conclusion: Mapping ALSWH health-related data to ICF components identified significant risk factors for falls are related to health conditions, functional limitations and home hazards. Biopsycho-social approaches guided by the ICF framework are crucial for fall prevention.

Keywords: Accidental Falls; Home Hazards; Activities of Daily Living; Participation; Occupational Therapy

\footnotetext{
"Declaration of interest: The authors report no conflicts of interest.
}

\section{INTRODUCTION}

Fall is a major source of morbidity and mortality in older people. Preventing falls is a key health priority. Fall is the second leading cause of accidental or unintentional injury deaths worldwide [1]. Injuries from falls contribute to increased disability and mobility limitations for older people, and therefore, as the proportion of the aged population increases, the research of the risk factors for falls is becoming increasingly important. The cost of hospitalizations due to fall related injury for people aged 65 and over is projected to increase to US $\$ 240$ billion by the year 2040 [2]. Due to the complexity of risk factors for falls, it is crucial to refine conceptual and methodological frameworks for understanding and predicting falls in the population to aid the formulation of more effective fall interventions. One such framework which may be applied to understanding and predicting risks of falls is the International Classification of Functioning, Disability and Health (ICF) [3].

The ICF is a classification system that documents the complex interactions of a person with his physical, social and psychological environments, and how this interaction affects his health status [3-5]. Together with the ICD10 [6], the World Health Organisation's diagnostic epidemiological, clinical and health management classification system, the ICF can describe health for an individual or a population and identify relationships between factors that are known to contribute to falls, or assist in detecting those most at risk [7]. The level of physical functioning experienced by an individual is an important factor in falls. The ICF's emphasis on personal functioning - on how an individual engages in activities and participates in society in the context of environmental and 
personal factors [3], and the dynamic interaction between health states, the person and his/her environment [3], makes it particularly suitable for extending understandings of falls and falls risk. As a classification framework for fall prediction and intervention, the ICF can conceivably provide an inter-professional scientific basis for understanding and studying fall behaviour and risk, and ensure that important concepts are identified and measured.

The ICF allows a comprehensive study of fall risk that includes medical, social and psychological risk factors. As fall risk is multidimensional, the ICF is appropriate to systematically investigate falls in the clinical practice [8]. Further, the ICF has already been embraced across a number of falls-related disciplines, such as occupational therapy and rehabilitation [7,9], but has not been specifically related to fall risk. The interactions between the ICF components are reciprocal. Therefore, the ICF accommodates the dynamic interactions underpinning fall risk, so that any change in one of the ICF components can influence other interactions within the framework. In a study of the ICF and clinical assessment measures in relation to falls following stroke [7], the ICF was found to match the multidimensional nature of fall risk. However, this relationship was not empirically tested. Furthermore, little evidence exists on how to reliably map the ICF to fall risk, or whether an analysis of fall risk using the ICF components is able to confirm the theoretical assumptions underpinning the ICF [10].

The Australian Longitudinal Study on Women's Health (ALSWH) is well positioned to explore the prevalence of falls and serious injury among a large sample of older women with varying degrees of health, wellbeing, mobility and functional capacities or limitations and disability within the Australian community, and to observe and study the antecedents and outcomes of falls over the course of the study [11]. An exploratory cross-sectional study of the baseline older cohort $(n=12,000)$ of the ALSWH demonstrated that serious falls were significantly associated with the physical component score of the SF36 (Short-form-36 Health Survey) [12], taking drugs for nerves, having had a serious life event other than a fall in the previous year, and feeling dejected [11]. These results suggested that psychological, social, and occupational factors consistent with the ICF were important to understand serious falls in older women. However, previous studies have argued that the ICF is limited by its failure to meaningfully address the influence of personal factors such as socioeconomic status and gender which are critical to understanding the lives of individuals [13], and by inherent difficulties such as those posed by a lack of differentiation between conceptual boundaries, for example, the boundaries between the concepts of Participation and Activity $[4,14]$. Further, it is argued that it is necessary to clarify these boundaries for the ICF to be scientifically useful for the empirical research [4]. We sought to map risk factors for falls (measured in the ALSWH) to the ICF, and to determine whether this conceptual model predicted falls statistically significantly.

\section{METHOD}

\subsection{Data Collection}

Participants in this study were drawn from the Australian Longitudinal Study on Women's Health (ALSWH), a population-based study of changes in health and wellbeing of three different age-cohorts of women living in Australia. The sample was randomly selected from the Medicare Australia database, which is the universal provider of health insurance in Australia [15], and surveys have been conducted at 3-yearly intervals since 1996. The study was approved by the University of Newcastle Human Research Ethics Committee. Further details on the ALSWH are available from the website,

www.alswh.org.au. For this study, 650 women were randomly selected from ALSWH participants who were born in 1921-1926, and who had completed Survey 3 in 2002.

Women in this sub-sample were invited to complete a postal survey collecting additional falls information including the Modified Falls Efficacy Scale [16], Fear of Falling scale [17,18], the Home Falls and Accidents Screening Tool (HOME FAST-SR) for measuring home hazards [19], and use of walking aids, and activities of daily living (Lambeth Disability Scale) [20]. This survey supplemented the data collected within the main ALSWH surveys known to be significantly related to falls. The outcome of falls was assessed in the sub-study and again in Survey 4 (2005) of the main study from the question: In the last 12 months have you had a fall to the ground (Yes, No). This self-report item has been shown to have reasonable sensitivity and specificity when compared with falls calendars [21].

\subsection{Mapping to the ICF}

Items included in the four main surveys and sub-study were mapped to the corresponding ICF components using ICF definitions (but not the levels of classification) [3] and the linking rules developed by Cieza [22,23]. These linking rules have been used in many studies [24-27] and were the only available tool to use in assigning the ALSWH survey items to the ICF components. Initial mapping was done by two of the authors who were occupational therapists (AM, LM) according to their interpretations of the meaning of the ICF and the linking rules. Demographic information, use of health services, lifestyle factors and living arrangements were mapped to personal factors, despite these being unclassi- 
fied within the ICF $[3,28]$.

\subsection{Longitudinal Analysis}

Univariate analyses (chi-square and t-tests) were applied to assess associations between the variables aligned to the ICF and self-reported falls at Survey 4. Explanatory variables were selected as those items measured on the sub-study or on the most recent survey prior to the sub-study. Most variables were measured at Survey 3 but some variables were measured at Survey 2 and education and country of birth were measured at Survey 1 (See Table 1). Correlation matrices [29] were constructed to identify highly correlated explanatory variables. Where variables were highly correlated, the variable most strongly associated with falls at the univariate level was retained for inclusion in the multivariate modelling.

Logistic regression was used to construct sub-models of factors associated with falls at Survey 4 for each ICF component. Variables with $\mathrm{P} \leq 0.3$ at the univariate level were included in multivariate analyses for each submodel, with backward stepwise removal of variables [30]. A final composite model was constructed by systematically combining each sub-model into a forward stepwise regression model-building process in order of the strongest Akaike Information Criteria (AIC) [31] for each submodel. The composite model examined statistically adjusted effects of the sub-models on the log odds of falls. A total of eight steps were conducted to create the final composite model from the sub-models. Statistical interactions between the strongest variables from each submodel were also explored. All these analyses were performed by Stata v8.2 [32] (StataCorp, 2004) and SAS v9.1 [33]. (SAS Institute, 2007).

\section{RESULTS}

\subsection{Results of the Mapping Process}

Table 1 shows a summary of the item categories contained within the four surveys of ALSWH, and their relationship to the ICF components after the mapping process was completed. Some scale items appear in multiple components of the ICF, due to the nature of each scale item.

\subsection{Sub-Study Survey and Cross-Sectional Analysis}

Out of the 650 surveys that were mailed out to the ALSWH participants, 568 surveys were returned (a response rate of $87.4 \%$ ). The demographic characteristics of sub-study participants are presented in Table 2. The mean age of participants was 79.7 years, and most participants were widowed and lived alone in their home. The sub-study sample was representative of the wider
ALSWH population. The outcomes of the additional falls variables included in the sub-sample survey are presented in Table 3. Generally, participants demonstrated relatively high levels of falls self-efficacy, low rates of functional disability, moderate numbers of home hazards, low levels of mobility aid usage and low rates of fear of falling.

\subsection{Multivariate Longitudinal Analysis}

The prevalence of falls experienced in the previous year at survey 4 was $20 \%(n=103)$. According to the AIC [31] the strongest sub-model was for health conditions (AIC 458.6), followed by body function (AIC 463.5), personal factors (AIC 472.3), environmental factors (AIC 475.8), general health (AIC 501.8), activity and participation (AIC 507.6), not-covered (AIC 520.7). The final composite model (step 8) is presented in Table 4.

After adjusting for all variables in the sub-models, the final composite model shows that participant health conditions significantly associated with falls were low iron levels and cataracts with diabetes being protective for falls. Women reporting a "major illness/injury in last three years" were about three times more likely to have a fall and those reporting "most time spent in chair/bed" were about twice as likely to have fall, after adjusting for all other variables.

The only items related to ICF components significantly associated with falls were using medication for high blood pressure (body functions), activities of daily living and instrumental activities of daily living as measured by the Lambeth Disability Scale (activity and participation) [20], and home hazards as measured by the self-rated version of the Home Falls and Accidents Screening Tool (HOME FAST-SR) (environment) [19].

In order to check the interaction terms, three significant variables from the strongest ICF model component "health condition" were assessed with the "HOME FAST-SR Score" from the environmental component and with the "Lambeth Disability Scale" from the activity \& participation ICF component. Checking the model using the Wald Chi Squared test revealed that none of the interactions were significant.

\section{DISCUSSION}

\subsection{Consistency of Identified Risk Factors for Falls with Previous Research}

The findings have confirmed many of the significant risk factors for falls in community populations, whilst other risk factors have not been confirmed with this sample. This study found cataracts were related to falls, consistent with other studies indicating visual problems 
Table 1. Summary of the ALSWH items in the surveys (1 - 3 and sub-study) mapped to the ICF.

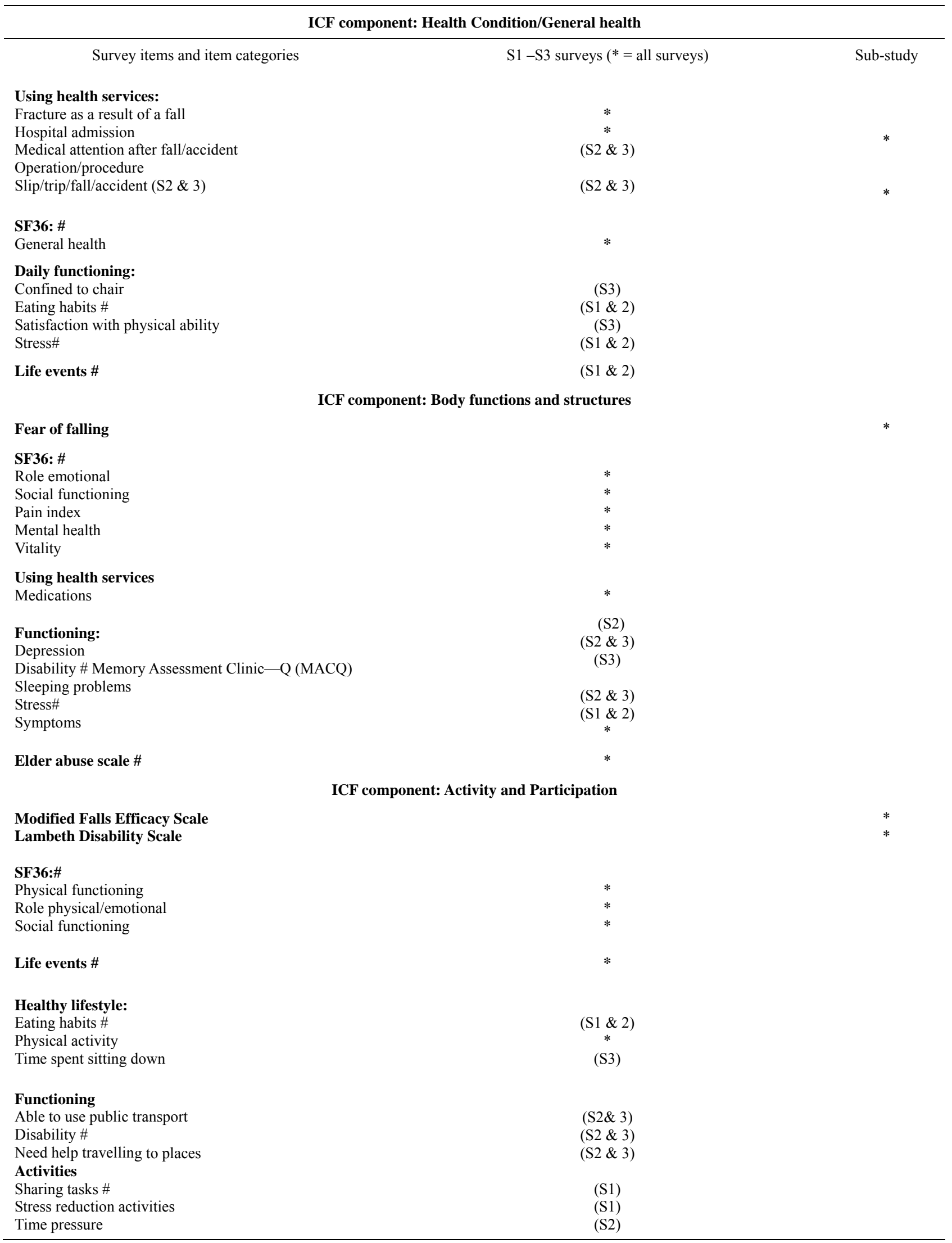




\begin{tabular}{|c|c|c|}
\hline \multicolumn{3}{|c|}{ ICF component: Environmental Factors } \\
\hline Survey items and item categories & Survey items and item categories & Survey items and item categories \\
\hline Home Falls and Accidents Screening Tool—SR & & * \\
\hline $\begin{array}{l}\text { Using health services: } \\
\text { GP cost } \\
\text { GP satisfaction } \\
\text { Health service access }\end{array}$ & $\begin{array}{l}(\mathrm{S} 2 \& 3) \\
(\mathrm{S} 1) \\
(\mathrm{S} 2 \& 3)\end{array}$ & \\
\hline Life events \# & * & \\
\hline $\begin{array}{l}\text { Daily life: } \\
\text { Assistance from organizations } \\
\text { Help with daily tasks } \\
\text { Main means of transport } \\
\text { Need for care } \\
\text { Problems with transport } \\
\text { Public transport availability }\end{array}$ & $\begin{array}{l}(\mathrm{S} 2 \& 3) \\
(\mathrm{S} 2) \\
(\mathrm{S} 3) \\
(\mathrm{S} 2 \& 3) \\
(\mathrm{S} 2 \& 3) \\
(\mathrm{S} 2 \& 3)\end{array}$ & \\
\hline $\begin{array}{l}\text { Home and neighbourhood: } \\
\text { Housing } \\
\text { Neighbourhood } \\
\text { Pets } \\
\text { Source of income }\end{array}$ & $\begin{array}{l}(\mathrm{S} 2 \& 3) \\
(\mathrm{S} 2) \\
(\mathrm{S} 2 \& 3) \\
(\mathrm{S} 2 \& 3)\end{array}$ & \\
\hline $\begin{array}{l}\text { Social support: } \\
\text { Duke Social Support Index } \\
\text { Elder abuse scale \# }\end{array}$ & $\begin{array}{l}* \\
*\end{array}$ & \\
\hline
\end{tabular}

\#indicates that variables have items allocated across more than one ICF component.

Table 2. Demographic characteristics of participants $(\mathrm{N}=568)$ compared to the ALSWH reference population $(\mathrm{N}=8418)$.

\begin{tabular}{|c|c|c|}
\hline & $\begin{array}{l}\text { Sub-study } \\
(\mathrm{N}=568)\end{array}$ & ALSWH population at survey $3(\mathrm{~N}=8418)$ \\
\hline \multicolumn{3}{|l|}{ Marital Status: } \\
\hline Married & $42 \%$ & $44 \%$ \\
\hline Widowed & $48 \%$ & $47 \%$ \\
\hline Other & $10 \%$ & $9 \%$ \\
\hline Lives alone & $52 \%$ & $47.5 \%$ \\
\hline \multicolumn{3}{|l|}{ State of residency } \\
\hline NSW & $37 \%$ & $34 \%$ \\
\hline Victoria & $23 \%$ & $25 \%$ \\
\hline Queensland & $18 \%$ & $18 \%$ \\
\hline South Australia & $9 \%$ & $10 \%$ \\
\hline Western Australia & $8 \%$ & $8 \%$ \\
\hline Other & $5 \%$ & $5 \%$ \\
\hline \multicolumn{3}{|l|}{ Location } \\
\hline Rural & $59 \%$ & $55 \%$ \\
\hline Urban & $39 \%$ & $43 \%$ \\
\hline Remote & $2 \%$ & $2 \%$ \\
\hline \multicolumn{3}{|l|}{ Type of Housing } \\
\hline House & $73 \%$ & $69 \%$ \\
\hline Flat/Unit/Apartment & $17 \%$ & $21 \%$ \\
\hline Retirement village & $9 \%$ & $8 \%$ \\
\hline Other & $1 \%$ & $1 \%$ \\
\hline
\end{tabular}

are an important risk factor for falls [34-38]. Harwood [38] reported a reduction in the rate of falls for those who received cataract surgery for the first eye, whereas surgery on a second eye has not been reported to reduce the rate of falls [39]. The finding that low iron levels increased fall risk is also consistent with other studies
[40.41]. The finding that high blood pressure medication increases the risk of falls is less straightforward, as this could be related to the underlying pathology of higher blood pressure or the effects of the medication, where antihypertensive (alpha blockers) drugs may increase the risk of falls [42]. 
Table 3. Fall-related measures used in the sub-study survey $(\mathrm{N}=568)$.

\begin{tabular}{|c|c|c|}
\hline Measure & Mean Score & $95 \%$ C.I \\
\hline $\begin{array}{l}\text { Modified Falls Efficacy Score }(\mathrm{n}=541) \\
\text { Possible score } 0 \text { - } 150 \\
\text { Higher scores indicate higher falls self-efficacy }\end{array}$ & 131.6 & $129.4-133.7$ \\
\hline $\begin{array}{c}\text { Lambeth Disability Scale }(\mathrm{n}=553) \\
\text { Possible score }=0-20 \\
\text { High scores indicate increased disability }\end{array}$ & 2.37 & $2.1-2.6$ \\
\hline $\begin{array}{l}\text { Home Falls and Accidents Screening Tool HOME FAST } \\
\qquad \begin{array}{l}-\mathrm{SR} \\
(\mathrm{N}=568)\end{array}\end{array}$ & 9.39 & $9.1-9.7$ \\
\hline & $\%$ & $\mathrm{n}$ \\
\hline Uses a walking stick for mobility & $11 \%$ & 63 \\
\hline $\begin{array}{l}\text { Fear of falling } \\
\text { Very Afraid } \\
\text { Fairly Afraid } \\
\text { A little Afraid } \\
\text { Not at all Afraid }\end{array}$ & $\begin{array}{c}4 \% \\
9 \% \\
52 \% \\
36 \%\end{array}$ & $\begin{array}{c}20 \\
48 \\
282 \\
194\end{array}$ \\
\hline
\end{tabular}

Table 4. Significant variables related to the outcome of falls at S4 within each component of the ICF in the final composite model (N $=453)^{*}$.

\begin{tabular}{|c|c|c|}
\hline ICF component & Variable & $\begin{array}{c}\text { Odds Ratio } \\
(95 \% \mathrm{CI})\end{array}$ \\
\hline \multirow[t]{4}{*}{ Health conditions and general health } & Diabetes & $0.14(0.04-0.55)$ \\
\hline & Low iron level & $2.00(1.03-3.91)$ \\
\hline & Cataract & $2.06(1.19-3.55)$ \\
\hline & Most time spent in chair/bed & $1.99(1.14-3.49)$ \\
\hline Body systems and structures & High blood pressure medication & $1.71(1.01-2.88)$ \\
\hline Activity and participation & Lambeth Disability Scale & $1.09(1.01-1.17)$ \\
\hline Environmental factors & HOME FAST_-SR score & $1.11(1.02-1.20)$ \\
\hline
\end{tabular}

\footnotetext{
${ }^{*} \mathrm{~N}=453$ due to missing data on some items included in the models.
}

One unanticipated finding was that having diabetes was a protective risk factor for falls for these women. This may be due to the adjustment of different variables (such as cataract) in the final model, and may represent the main mechanism by which diabetes results in falls. Furthermore, $22 \%$ of diabetics in the ALSWH study were controlled by diet or exercise alone and these women may have fewer complications that could have contributed to a falls. In addition, women with diabetes may have visited their physician or other health care professional more frequently, placing them in a better position to access services that would also protect them from falls. Findings from other research is mixed, with some studies concluding that diabetes is a positive risk factors for falls, especially for people who are insulin dependent [43] with other studies concluding that diabe- tes is not a significant factor contributing to falls $[44,45]$.

The identification of risk factors for falls for this sample may also be related to the lower prevalence of falls reported by participants $(20 \%)$, compared to other studies of community-dwelling older people. The older women in this study demonstrated better health and higher levels of functioning that may have contributed to a lower reported prevalence of falls.

\subsection{Hazardous Home Environments Contribute to Falls}

The HOME FAST-SR score [19] was the only significant variable in the ICF environmental component related to falls and further supports the use of this self-report tool to determine home hazards for older people at risk of falls. Findings indicate that living in a haz- 
ardous home environment increases the risk of falls for older people, and at each increase in the HOME FASTSR score, there is an $11 \%$ increase in the odds of a fall. The contribution of modifying the home environment to reduce the risk of falls has been investigated. A metaanalysis by Clemson et al. [46] concluded that single home modification interventions are effective for both high and low risk fallers, whereas Gillespie et al. [47] concluded that home hazard assessment and management are effective for high risk fallers only. These findings indicate that hazardous home environments remain a significant risk factor for a population of older women who are functioning well in the community.

\subsection{The Importance of Functional Activities}

Instrumental ADL and personal ADL as measured by the Lambeth Disability Scale [20] were significantly associated with falls in this sample. As difficulty in IADL tasks precedes ADL difficulties [48], this scale was relevant to a community population of relatively healthy older women. Difficulty in ADL and IADL tasks can be both a consequence and a risk factor for falls [49], and this study suggests that functional difficulties can be an early indicator for falls risk. The item relating to time spent in a bed or chair was mapped to the general health category, but also indicated severe mobility limitations that were significantly associated with falls. It could be argued that the environment is an important component of independence in ADL \& IADL, however the interaction terms used in the longitudinal analysis did not indicate that the two components were significantly related.

\subsection{Application of the ICF to Falls Risk}

Findings demonstrate that falls in a community sample of older women are associated with a wide range of health, functional and environmental factors that are consistent with the ICF classification. Six out of the eight final significant variables were related to specific health/ medical conditions which were not explicitly covered in the linking process. These items are important aspects to screen for and monitor to prevent falls. The inclusion of significant functional and environmental variables in the final model indicates that these should also be identified to reduce falls risk in community populations. The study demonstrated that whilst the ICF was developed as a classification system, it is a valid framework to use to guide future studies related to falls risk in a community population.

However, the study identified some issues in utilising the ICF as a framework. The mapping process highlighted difficulties with the conceptual distinctions between activity and participation [4,50,51]. Reduced activity is a falls risk [52] and a lack of participation in meaningful roles or alienation from the community is also identified as a separate risk factor [11]. The lack of detail within the ICF about personal factors is also an issue. Cerniauskaite et al. [53] identified a clear need to define and develop personal factors within the ICF classification framework that might be considered risk factors for disease development or have negative effects on individual functioning. Many concepts related to personal aspects of an individual are an important part of understanding falls, for instance, levels of risk taking behaviour. Personal factors listed in the ICF such as gender, age, and living alone are known to have a role in falls risk [54]. However, important personal factors that determine increased falls risk may extend beyond the factors listed in the ICF classification and include unique, individual features associated with a person-centred approach to health professional practice [55]. Therefore, without their inclusion, using the ICF is bound to underestimate the contribution of personal factors to the outcome of falls risk.

The fundamental process for this study was the linking of ICF components to the items from the ALSWH surveys and the sub-study. The intuitive process used by the researchers to link items did not always agree with the ICF linking rules, which were used as the final authority to link items. As there were no anatomical structures explicitly assessed in the ASLWH data, similar items could only be linked with body functions. The linking rules led to a large number of items being allocated to the body function component, whereas specific medical conditions were not covered. Furthermore, the linking rules required several standardised measures such as the SF36 to be broken up so that different items could be allocated to different ICF components (see Table 1). This may have ramifications for the interpretation of the constructs that the tools were originally designed to measure.

\subsection{Strengths and Limitations of the Study}

This study had several strengths. Falls were measured in a randomly selected nested sub-study from a large national cohort, over an extended period of follow-up. Participants were living in urban, rural and remote areas representative of the diversity of Australian living conditions, access to health care, and other social aspects. Data were available on a range of risk factors known to be associated with falls. Ideally, a survey designed specifically to test the ICF would have allowed items to be directly linked to the ICF, but such a survey may not have included some variables that were significant in the final model.

Limitations of the study include data obtained through self-report, therefore some misclassifications may have occurred due to under or over-reporting of health issues 
[21]. Under-reporting is more likely, and would have led to weakening any real associations with falls. The falls outcome was also measured by self-report, and the prevalence of falling was the study factor, as opposed to the number of falls reported. The participants in this study were volunteers and were relatively healthy community-dwelling women; therefore the study results are not generalisable to the broader population of older people, especially older men. There were high rates of missing values for some data items, and where possible this was managed by replacing data using logic checks for important variables. This may have led to some limitations in the analysis.

\section{CONCLUSION}

In this study, the access to the ALSWH data set allowed the ICF to be tested with a broadly representative population of older women. Key risk factors that were significantly associated with falls included health conditions, functional limitations in IADL and ADL and hazardous home environments, which suggested that any population-based fall studies should include person-related factors, activity and participation factors and environmental factors. Further classification work of personal factors needs to be done. The ICF framework is updated to reflect the contribution of personal factors such as gender, education, life style, habits and socio-economic status in relation to falls risk. This will allow for more consistency, accuracy and ease of use of the definition of fall by health professionals in their everyday practice.

\section{REFERENCES}

[1] World Health Organisation (2010) Falls. Fact Sheet 344. http://www.who.int/mediacentre/factsheets/fs344/en

[2] World Health Organisation (2007) Global report on falls prevention in older age. World Health Organization, Geneva.

[3] World Health Organization (2001) International Classification of Functioning, Disability and Health: ICF. World Health Organization, Geneva.

[4] Jette, A., Haley, S. and Kooyoomjianet, J. (2003) Are the ICF activity and participation dimensions distinct? Journal of Rehabilitation Medicine, 35, 145-149. http://dx.doi.org/10.1080/16501970310010501

[5] Simeonsson, R., Lollar, D., Hollowell, J. and Adams, M. (2000) Revision of the international classification of impairments, disabilities, and handicaps: Developmental issues. Journal of Clinical Epidemiology, 53, 113-124. http://dx.doi.org/10.1016/S0895-4356(99)00133-X

[6] World Health Organisation (2007) International classification of diseases: ICD-10. World Health Organisation, Geneva.

[7] Bennineto, M., Portneym, L. and Sullivan, P. (2009) Us- ing the International Classification of Functioning, Disability and Health as a framework to examine the association between falls and clinical assessment tools in people with stroke. Physical Therapy, 89, 816-825.

http://dx.doi.org/10.2522/ptj.20080160

[8] Cieza, A., Hilfiker, R., Chatterji, S., Kostanjsek, N., Üstün, B and Stucki, G. (2009) The International Classification of Functioning, Disability and Health could be used to measure functioning. Journal of Clinical Epidemiology, 62, 899-911. http://dx.doi.org/10.1016/i.jclinepi.2009.01.019

[9] Darzins, P., Fone, S and Darzins, S. (2006) The International Classification of Functioning, Disability and Health can help to structure and evaluate therapy. Australian Occupational Therapy Journal, 53,127-131. http://dx.doi.org/10.1111/j.1440-1630.2006.00580.x

[10] Mackenzie, L., Hassani Mehraban, A., Byles, J. and Gibson, R. (2010) Can the International Classification of Functioning, Disability and Health (ICF) be used as a framework to explain falls in older Australian women? www.wfot.org.au/wfot2010/program/pdf/0224.pdf

[11] Mackenzie, L., Byles, J and Mishra, G. (2004) An occupational focus on falls with serious injury among older women in Australia. Australian Occupational Therapy Journal, 51, 144-154. http://dx.doi.org/10.1111/j.1440-1630.2004.00424.x

[12] Ware, J and Sherbourne, C. (1992) The MOS 36-item short form health survey (SF-36): Conceptual framework and item selection, Part 1. Medical Care, 30, 473-481. http://dx.doi.org/10.1097/00005650-199206000-00002

[13] Conti-Becker, A. (2009) Between the ideal and the real: Reconsidering the International Classification of Functioning, Disability and Health. Disability and Rehabilitation, 31, 2125-2129. http://dx.doi.org/10.3109/09638280902912509

[14] Grimby, G and Smedby, B. (2001) ICF approved as the successor of ICIDH (editorial). Journal of Rehabilitation Medicine, 33, 193-194. http://dx.doi.org/10.1080/165019701750419545

[15] Lee, C., Dobson, A. and Brown, W. (2005) Cohort profile: The australian longitudinal study on women's health. International Journal of Epidemiology, 34, 987-991. http://dx.doi.org/10.1093/ije/dyi098

[16] Hill, K., Schwarz, J., Kalogeropoulos, A. and Gibson, S. (1996) Fear of falling revisited. Archives of Physical Medicine and Rehabilitation, 77, 1025-1029. http://dx.doi.org/10.1016/S0003-9993(96)90063-5

[17] Howland, J., Peterson, E., Levin, W., Fried, L., Pordon, D. and Bak, S. (1993) Fear of falling among the community-dwelling elderly. Journal of Aging and Health, 5, 229-243. http://dx.doi.org/10.1177/089826439300500205

[18] Howland, J., Lachman, M., Peterson, E., Cote, J., Kasten, L. and Jette, A. (1998) Covariates of fear of falling and associated activity curtailment. The Gerontologist, 38, 549-555. http://dx.doi.org/10.1093/geront/38.5.549

[19] Hassani Mehraban, A., Mackenzie, L. and Byles, J. (2011) A self-report home environment screening tool identified older women at risk of falls. Journal of Clinical Epidemi- 
ology, 64, 191-199.

http://dx.doi.org/10.1016/j.jclinepi.2010.02.013

[20] Charlton, J., Patrick, D. and Peach, H. (1983) Use of multivariate measures of disability in health surveys. Journal of Epidemiology \& Community Health, 37, 296304. http://dx.doi.org/10.1136/jech.37.4.296

[21] Mackenzie, L., Byles, J. and D'Este, C. (2006) Validation of self-reported fall events in intervention studies. Clinical Rehabilitation, 20, 331-339. http://dx.doi.org/10.1191/0269215506cr947oa

[22] Cieza, A., Brockow, T. and Ewert, T. (2002) Linking health-status measurements to the International Classification of Functioning, Disability and Health. Journal of Rehabilitation Medicine, 34, 205-210. http://dx.doi.org/10.1080/165019702760279189

[23] Cieza, A., Geyh, S. and Chatterji, S. (2005) ICF linking rules: An update based on lessons learned. Journal of Rehabilitation Medicine, 37, 212-218. http://dx.doi.org/10.1080/16501970510040263

[24] Sigl, T., Cieza, A. and Brockow, T. (2006) Content comparison of low back pain-specific measures based on the International Classification of Functioning, Disability and Health (ICF). The Clinical Journal of Pain, 22, 147-153. http://dx.doi.org/10.1097/01.ajp.0000155344.22064.f4

[25] Stamm, T., Cieza, A. and Stucki, G. (2006) Exploration of the link between conceptual occupational therapy models and the International Classification of Functioning, Disability and Health. Australian Occupational Therapy Journal, 53, 9-17. http://dx.doi.org/10.1111/j.1440-1630.2006.00573.x

[26] Stucki, A., Stucki, G., Cieza, A., Schuurmans, M., Kostanjsek, N. and Ruof, J. (2007) Content comparison of health-related quality of life instruments for COPD. Respiratory Medicine, 101, 1113-1122. http://dx.doi.org/10.1016/j.rmed.2006.11.016

[27] Weigl, M., Cieza, A. and Harder, M. (2003) Linking osteoarthritis-specific health status measures to the International Classification of Functioning, Disability and Health (ICF). Osteoarthritis and Cartilage, 11, 519-523. http://dx.doi.org/10.1016/S1063-4584(03)00086-4

[28] Australian Institute Health \& Welfare (AIHW) (2003) ICF Australian user guide, V.1.0. http://www.aihw.gov.au/WorkArea/DownloadAsset.aspx? $\mathrm{id}=6442475185$

[29] Drasgow, F. (2004) Polychoric and polyserial correlations. In: Kotz, L. and Johnson, N., Eds., Encyclopedia of Statistical Sciences, Wiley, New York, 68-74. http://dx.doi.org/10.1002/0471667196.ess2014

[30] Hosmer, D and Lemshow, S. (2000) Applied logistic regression. 2nd Edition, Wiley-Interscience, John Wiley \& Sons Inc., Hoboken. http://dx.doi.org/10.1002/0471722146

[31] Akaike, H. (1974) A new look at the statistical model identification. IEEE Transactions on Automatic Control, 19, 716-723. http://dx.doi.org/10.1109/TAC.1974.1100705

[32] Stata Statistical Software (2004) (Version 8.2) Stata Corporation, College Station.
[33] SAS (2007) (Version 9.1) [software]. SAS Institute, Carey.

[34] Abdelhafiz, A. and Austin, C. (2003) Visual factors should be assessed in older people presenting with falls or hip fracture. Age and Ageing, 32, 26-30. http://dx.doi.org/10.1093/ageing/32.1.26

[35] Campbell, A., Robertson, M. and La Grow, S. (2005) Randomised controlled trial of prevention of falls in people aged $>75$ with severe visual impairment: The VIP trial. British Medical Journal, 331, 817-824.

http://dx.doi.org/10.1136/bmj.38601.447731.55

[36] Lord, S., Ward, J. and Williams, P. (1993) An epidemiological study of falls in older community-dwelling women: The Randwick falls and fractures study. Australian and New Zealand Journal of Public Health, 17, 240-245.

[37] Harwood, R. (2001) Visual problems and falls. Age and Ageing, 30, 13-18. http://dx.doi.org/10.1093/ageing/30.suppl 4.13

[38] Harwood, R., Foss, A., Osborn, F., Gregson, R., Zaman, A. and Masud, T. (2005) Falls and health status in elderly women following first eye cataract surgery: A randomised controlled trial. British Journal of Ophthalmology, 89, 53-59. http://dx.doi.org/10.1136/bjo.2004.049478

[39] Foss, A., Harwood, R., Osborn, F., Gregson, R., Zaman, A. and Masud, T. (2006) Falls and health status in elderly women following second eye cataract surgery: A randomised controlled trial. Age and Ageing, 35, 66-71. http://dx.doi.org/10.1093/ageing/afj005

[40] Dharmarajan, T., Auula, S. and Norkus, E. (2006) Anaemia increases risk for fall in hospitalized older adults: An evaluation on falls in 362 hospitalized, ambulatory, long term care, and community patients. Journal of American Medical Directors Association, 7, 287-293. http://dx.doi.org/10.1016/j.jamda.2005.10.010

[41] Penninx, B., Pluijm, S. and Lips, P. (2005) Late-life anaemia is associated with increased risk of recurrent falls. Journal of the American Geriatrics Society, 53, 2106-2111. http://dx.doi.org/10.1111/j.1532-5415.2005.00491.x

[42] Hartikainen, S., Lonnroos, E. and Louhivuori, K. (2007) Medication as a risk factor for fall: Critical systematic review. Journals of Gerontology A Biological Sciences Medical Sciences, 62, 1172-1181.

[43] Schwartz, A., Hillier, T. and Sellmeyer, D. (2002) Older women with diabetes have a higher risk of falls. A prospective study. Diabetes Care, 25, 1749-1754. http://dx.doi.org/10.2337/diacare.25.10.1749

[44] Herndon, J., Helmick, C. and Sattin, R. (1997) Chronic medical conditions and risk of fall injury events at home in older adults. Journal of the American Geriatrics Society, 45, 739-743.

[45] van Daele, P., Stolk, R. and Burger, H. (1995) Bone density in non-insulin-dependent diabetes mellitus: The rotterdam study. Annals of Internal Medicine, 122, 409414.

http://dx.doi.org/10.7326/0003-4819-122-6-199503150-0 $\underline{0002}$

[46] Clemson, L., Mackenzie, L., Ballinger, C., Close, J. and 
Cumming, R. (2008) Environmental interventions to prevent falls in community dwelling older people: A metaanalysis of randomized trials. Journal of Aging and Health, 20, 954-71.

http://dx.doi.org/10.1177/0898264308324672

[47] Gillespie, L., Robertson, M. and Gillespie, W. (2012) Interventions for preventing falls in older people living in the community. Cochrane Database of Systematic Reviews, Article ID: CD007146. http://dx.doi.org/10.1002/14651858.CD007146.pub3

[48] Judge, J., Schechman, K. and Cress, E. (1996) The relationship between physical performance measures and independence in instrumental activities of daily living. The FICSIT group. Frailty and injury: co-operative studies of intervention trials. Journal of the American Geriatrics Society, 44, 1332-1341.

[49] Wojszel, Z. and Bien, B. (2004) Falls amongst older people living in the community. Annales Academiae Medicae Bialostocensis, 49, 280-284.

[50] Bruyère, S. and Van Looy, S. (2005) The International Classification of Functioning, Disability and Health: Contemporary literature overview. Rehabilitation Psychology, 50, 113-121. http://dx.doi.org/10.1037/0090-5550.50.2.113
[51] Nordenfelt, L. (2003) Action theory, disability, and ICF. Disability and Rehabilitation, 25, 1075-1079. http://dx.doi.org/10.1080/0963828031000137748

[52] Chan, B., Marshall, L., Winters, K., Faulkner, K., Schwartz, A. and Orwoll, E. (2007) Incident fall risk and physical activity and physical performance among older men. American Journal of Epidemiology, 165, 696-703. http://dx.doi.org/10.1093/aje/kwk050

[53] Cerniauskaite, M., Quintas, R. and Boldt, C. (2011) Systematic literature review on ICF from 2001 to 2009: Its use, implementation and operationalisation. Disability and Rehabilitation, 33, 281-309. http://dx.doi.org/10.3109/09638288.2010.529235

[54] National Collaborating Centre for Nursing and Supportive Care (2004) Clinical guideline 21, falls: The assessment and prevention of falls in older people. National Institute for Clinical Excellence, London.

[55] Geyh, S., Peter, C. and Müller, R. (2011) The personal factors of the International Classification of Functioning, Disability and Health in the literature-A systematic review and content analysis. Disability and Rehabilitation, 33, 1089-1102.

http://dx.doi.org/10.3109/09638288.2010.523104 